\title{
The Role of HRCT in Evaluation of Thoracic Manifestations of Collagen Vascular Diseases
}

\author{
YOUSSRIAH Y. SABRI, M.D.*; MAI B. IBRAHIM, M.D.*; REEM H. ABD-AL LATIF, M.D.** and \\ MAHA M. HUSSEIN, M.Sc.* \\ The Department of Diagnostic and Intervention Radiology* and Rheumatology \& Immunology Department**, \\ Faculty of Medicine, Cairo University, Egypt
}

\begin{abstract}
Background: High-resolution computed tomography has proven to play a basic role in the detection and characterization of various pulmonary lesions (interstitial, small air way disease etc.) in patients with collagen vascular diseases. Accurate HRCT detection of pulmonary involvement in collagen vascular disease has important therapeutic and prognostic implications.
\end{abstract}

Aim of Study: The aim of this study is to evaluate role of HRCT in diagnosis of thoracic manifestation of collagen vascular diseases.

Patients and Methods: 100 patients diagnosed as collagen vascular disease were referred to Radiology Department in Faculty of Medicine, Cairo University for HRCT of the chest.

Results: Interstial lung disease was seen in 48 patients $(48 \%)$, while 31 patients $(31 \%)$ showed signs of small airway disease.

Conclusion: HRCT is fundamental for evaluation of all thoracic manifestation of collagen vascular diseases.

Key Words: HRCT - Collagen vascular diseases (CVD).

\section{Introduction}

COLLAGEN vascular diseases are a heterogeneous group of immunologically mediated inflammatory disorders that may affect various organs [1]

Pulmonary alterations (physiologic or anatomic) may be the first manifestations of collagen vascular disease [2].

Accurate detection of pulmonary involvement in collagen vascular disease has important therapeutic and prognostic implications because prompt treatment may lead to improved outcomes [2].

Correspondence to: Dr. Youssriah Y. Sabri, The Department of Diagnostic and Intervention Radiology, Faculty of Medicine, Cairo University, Egypt
The collagen vascular diseases that most commonly involve the lung are rheumatoid arthritis, scleroderma, systemic lupus erythematosus, polymyositis and dermatomyositis, mixed connective tissue disease, and Sjögren syndrome [3,4] .

The pulmonary manifestations detected by HRCT in case of CVD include diffuse lung involvement (Interstial lung disease, small airway disease, Pulmonary macronodules), oesophageal abnormalities, pleural and pericardial effusions and thickening, pulmonary arterial enlargement, mediastinal lymphadenopathy [5]

The two thoracic manifestations with the greatest clinical importance in patients with collagen vascular diseases are interstitial lung disease and pulmonary arterial hypertension, which are responsible for a large part of the mortality and morbidity in this patient group. Nonspecific interstitial pneumonia has been found to be the most common histological pattern of ILD in patients with collagen vascular diseases [6].

Aim of the work:

The aim of the work is to evaluate the role of High resolution computed tomography of lungs in

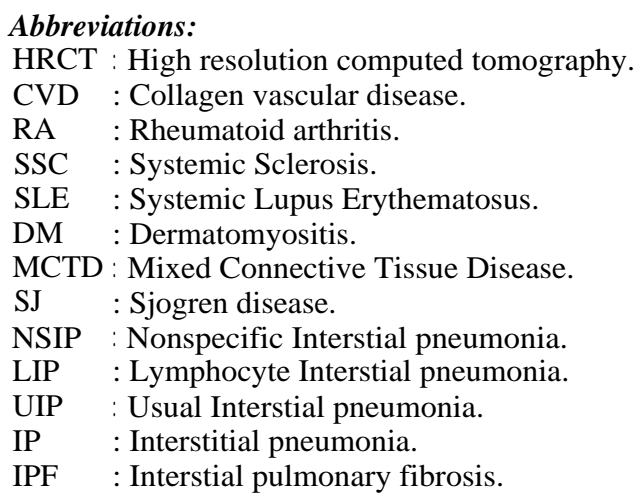


diagnosis of thoracic manifestations of collagen vascular Diseases.

\section{Patients and Methods}

The study was conducted in the period from January 2017 to January 2019 in Radiology Department in Kasr Al Ainy Hospital.

This cross sectional study included 100 patients 12 males and 88 females with age range from 13 to 72 years (mean age of 40.66 years) with collagen vascular disease according to International diagnostic criteria (7) presenting with clinical symptoms suggesting lung affection as progressive dyspnea and chronic cough (Table 1). HRCT of the lungs was done to all patients as requested.

Table (1) Chest main complaints among CVD cases of this study.

They were referred from the outpatient clinic of Rheumatology and Immunology and Chest departments in Kasr Al Ainy Hospital to perform HRCT of lungs in the Radiology Department.

Table (2) Number and percent of cases per collagen disease with gender distribution.

\section{Inclusion criteria:}

Patients diagnosed as collagen vascular disease, according to International diagnostic criteria as relayed from records of inpatients in Rheumatology and Immunology department, who presented with symptoms suspicious of pulmonary affection (Table $1)$.

\section{Exclusion criteria:}

- Patient with known associated chest diseases and non-immune mediated pulmonary pathology e.g. tuberculosis.

- Patients with history of smoking.

- Patients with Sarcoidosis.

The study was approved by the ethical committee and informed consent was obtained assuring respect of the confidentiality of the medical records.

\section{Methods:}

HRCT chest was done to all patients using 16 channels MSCT (simens) in Kasr Al-Ainy. Reconstructed axial, coronal and sagittal images were done to all patients; also complementary mediastinal images were taken (see Table 3 for HRCT technique used in this study).

Table (3) HRCT techniques used in this study.

\section{Statistics:}

The package of statistical analysis used was SPSS version 21 . The data was coded, entered on excel sheet and analyzed by SPSS. Numerical data was presented by mean and standard deviation. Qualitative data was presented by frequency and percentage. Non-parametric tests as chi-squared test and ficher exact test were used on cells less than $50 \%$.

Table (1): Chest main complaints among CVD cases of this study.

\begin{tabular}{llll}
\hline Disease & Dyspnea & Dry cough & Expectoration \\
\hline RA & $20(64.5 \%)$ & $8(25.9 \%)$ & $3(9.6 \%)$ \\
SSc & $17(60.7 \%)$ & $9(32.3 \%)$ & $2(7 \%)$ \\
SLE & $15(62.5 \%)$ & $6(25 \%)$ & $3(12.5 \%)$ \\
DM & $7(87.5 \%)$ & $1(12.5 \%)$ & $0(0 \%)$ \\
MCTD & $6(75 \%)$ & $1(12.5 \%)$ & $1(12.5 \%)$ \\
SJ & $1(100 \%)$ & $0(0 \%)$ & $0(\%)$ \\
\hline
\end{tabular}

Table (2): Number and percent of cases per collagen disease with gender distribution.

\begin{tabular}{lccc}
\hline \multirow{2}{*}{ CVD } & $\begin{array}{c}\text { No.of patients } \\
\text { and percentage } \\
\text { of total cases }\end{array}$ & $\begin{array}{c}\text { Females } \\
\text { no. }\end{array}$ & $\begin{array}{c}\text { Males } \\
\text { no. }\end{array}$ \\
\cline { 3 - 4 } & $31(31 \%)$ & 25 & 6 \\
RA & $28(28 \%)$ & 27 & 1 \\
SSc & $24(24 \%)$ & 22 & 2 \\
DME & $8(8 \%)$ & 6 & 2 \\
MCTD & $8(8 \%)$ & 7 & 1 \\
SJ & $1(1 \%)$ & 1 & 0 \\
\hline
\end{tabular}

Table (3): HRCT techniques used in this study.

\begin{tabular}{ll}
\hline \multicolumn{2}{c}{ Conventional HRCT } \\
\hline Scout & Kv 130 \\
& mA 25 \\
& Holding breath \\
Scan type Helical & \\
Detector Row 16 & \\
Pitch 1.25mm & \\
Detector configuration 16x0.6 & \\
Beam collimation 5.0mm & \\
Gantry tilt 0.0 & \\
FOV Depends on the Patient size & \\
Reconstructed images & \\
Axial, sagittal and coronal HRCT images \\
WW 1000 WL-700 \\
Axial MIP images. \\
Axial mediastinal window images.
\end{tabular}




\section{Results}

Interstial lung disease in the form of interstial pneumonia were encountered in 48 patients $(48 \%$ of cases). They showed bilateral symmetrical predominately sub-pleural basal lesions with involvement of pleural recesses. The types of IP encountered ere UIP, NSIP and LIP. Table (4) shows the distribution of these entities among the patients of collagen vascular diseases.

On HRCT Usual Interstitial pneumonia (UIP) is characterized by the presence of reticular opacities, often associated with traction bronchiectasis. Architectural distortion suggestive of lung fibrosis is also frequently recognized (Fig. 1). Groundglass attenuation, if present, is less extensive than reticular abnormality. In advanced stages of IPF, honeycombing and lower lung volume loss are usually prominent $[8]$.

The most common features seen at highresolution computed tomography (CT) in NSIP cases are ground-glass opacities; reticular abnormalities, which usually represent fine fibrosis; and traction bronchiectasis or bronchiolectasis, which is almost universal in patients with fibrotic NSIP (Fig. 2) [9]

Other findings include the presence of consolidation and honeycomb cysts are usually less prominent in NSIP than in UIP [9].

Ground-glass opacities and nodules are almost universal features in LIP (Fig. 3) with cysts seen in about two-thirds of patients [10].

Table (4) Incidence of different types of IP among each CVD entity.

Airway disease was detected in 31 (31\%) of patients. Signs of airways diseases include hyperlucency, bronchial wall thickening, mosaic pattern and centrilobular nodules (Fig. 4). HRCT signs of airway affection in different CVD entity is shown in (Table 5).

Table (5) HRCT signs of airway disease among each CVD entity.

Pulmonary hypertension was recorded in 33 patients (33\%) (Table 6) illustrating the incidence of pulmonary hypertension in different CVD.

Table (6) Incidence of pulmonary hypertension among different types of CVD in this study.

Cardiomegaly was noted in $17 \%$ of CVD cases (Table 7) to see incidence of cardiomegaly in different CVD.

Table (7) Incidence of cardiomegaly among each CVD entity.
Thirty-three of studied cases $(33 \%)$ had pericardial affection (Fig. 5) in form of effusion or thickening (Table 8).

Pleural affection was recorded in 12 of studied cases (12\%) (Table 8).

Mediastinal lymph node enlargement was noted in $34 \%$ of cases (Table 8 ).

Esophageal abnormality was recorded in $28 \%$ of cases in form of patulous thoracic esophagus and/or presence of air fluid level within (Table 8).

Table (8) shows the incidence of different HRCT pulmonary lesions in CVD cases.

Table (4): Incidence of different types of IP among each CVD entity.

\begin{tabular}{lccc}
\hline Disease & UIP & NSIP & LIP \\
\hline RA & 7 & 4 & 1 \\
SSc & 7 & 13 & 2 \\
SLE & 1 & 4 & 0 \\
DM & 1 & 1 & 0 \\
MCTD & 4 & 2 & 0 \\
SJ & 0 & 0 & 1 \\
\hline
\end{tabular}

Table (5): Distribution of signs of airway affection among each CVD entity.

\begin{tabular}{lcccc}
\hline Disease & Hyperlucency & $\begin{array}{c}\text { Bronchial } \\
\text { wall } \\
\text { thickening }\end{array}$ & $\begin{array}{c}\text { Mosaic } \\
\text { pattern }\end{array}$ & $\begin{array}{c}\text { Centrilobular } \\
\text { nodules }\end{array}$ \\
\hline RA & 3 & 4 & 1 & 4 \\
SSc & 7 & 12 & 3 & 14 \\
SLE & 2 & 4 & 2 & 3 \\
DM & 3 & 3 & 0 & 1 \\
MCTD & 0 & 4 & 2 & 2 \\
SJ & 0 & 0 & 0 & 0 \\
\hline
\end{tabular}

Table (6): Incidence of pulmonary hypertension among different types of CVD in this study.

\begin{tabular}{lc}
\hline Disease & $\begin{array}{c}\text { Pulmonary } \\
\text { hypertension }\end{array}$ \\
\hline RA & 10 \\
SSc & 11 \\
SLE & 2 \\
DM & 5 \\
MCTD & 4 \\
SJ & 1 \\
\hline
\end{tabular}

Table (7): Incidence of cardiomegaly among each CVD entity.

\begin{tabular}{ll}
\hline Disease & Cardiomegaly \\
\hline RA & $1(3.2 \%)$ \\
SSc & $7(25 \%)$ \\
SLE & $6(25 \%)$ \\
DM & $1(12.5 \%)$ \\
MCTD & $2(25 \%)$ \\
SJ & 0 \\
\hline
\end{tabular}


Table (8): Collective incidence of each thoracic manifestation among each CVD group.

\begin{tabular}{lllllll}
\hline Disease & RA & SSc & SLE & DM & MCTD & SJ \\
\hline IP & $39 \%$ & $78.5 \%$ & $20 \%$ & $25 \%$ & $75 \%$ & $100 \%$ \\
Airway disease & $13 \%$ & $50 \%$ & $25 \%$ & $37.5 \%$ & $50 \%$ & $0 \%$ \\
Pulmonary hypertension & $33 \%$ & $32 \%$ & $8 \%$ & $62.5 \%$ & $50 \%$ & $100 \%$ \\
Pericardial affection & $16 \%$ & $28.5 \%$ & $62.5 \%$ & $37.5 \%$ & $25 \%$ & $0 \%$ \\
Pleural affection & $6.4 \%$ & $3.5 \%$ & $33.3 \%$ & $0 \%$ & $12.5 \%$ & $0 \%$ \\
Cardiomegaly & $3 \%$ & $25 \%$ & $25 \%$ & $12.5 \%$ & $25 \%$ & $0 \%$ \\
Mediastinal lymphadenopathy & $35 \%$ & $28.5 \%$ & $25 \%$ & $0 \%$ & $0 \%$ & $0 \%$ \\
Esophageal dysmotility & $9 \%$ & $82 \%$ & $25 \%$ & $0 \%$ & $0 \%$ & $0 \%$ \\
\hline
\end{tabular}
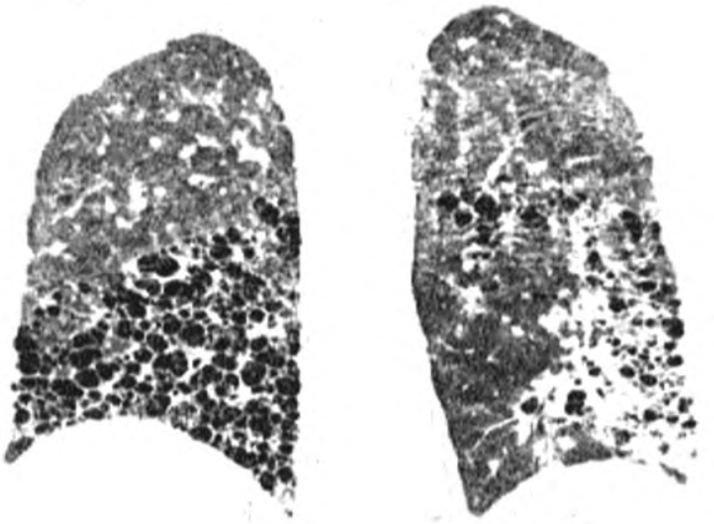

(A)

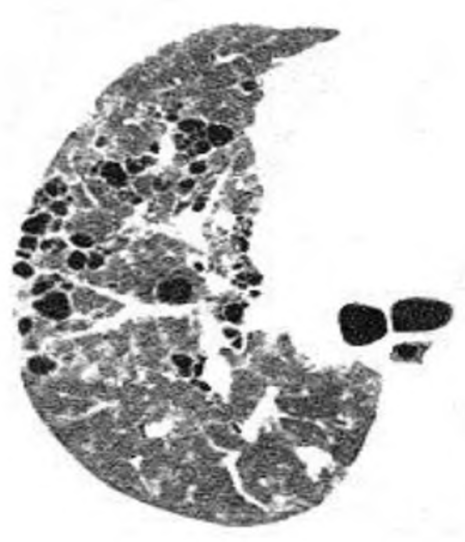

(B)

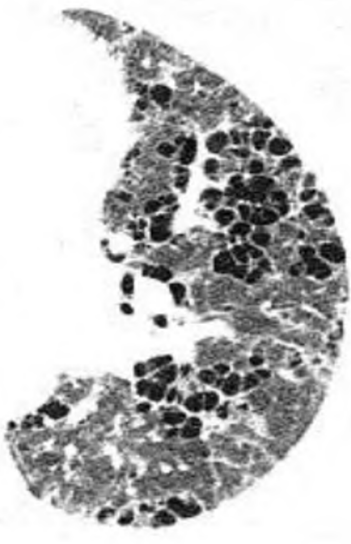

Fig. (1): 49-year-old female patient known case of Scleroderma presenting with progressive dyspnea on mild exertion and dry cough. (A) Coronal image, (B) Axial image show bilateral fairly symmetrical sub pleural predominantly basal honeycombing, filling pleural recesses. Picture impressive of UIP.

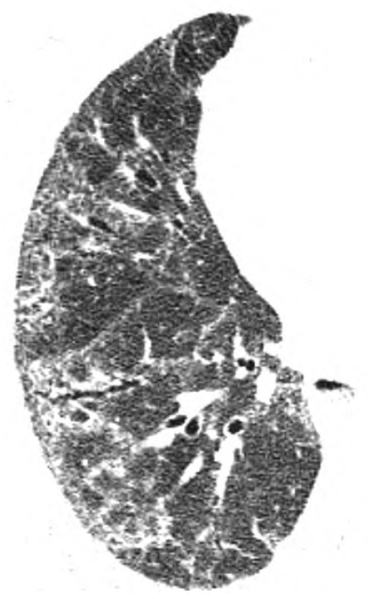

(A)

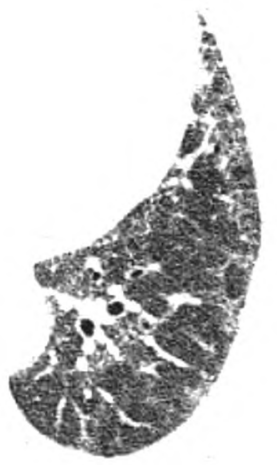

A)

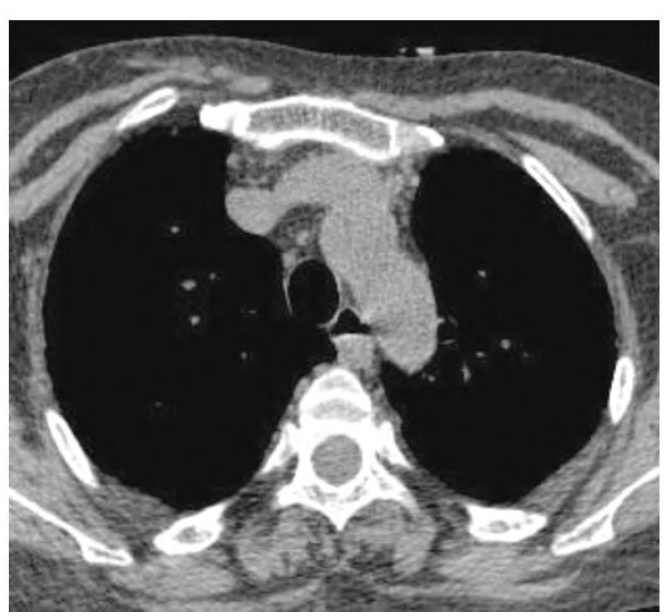

(B)

Fig. (2): 53-year-old female patient known case of Scleroderma presenting with dyspnea on minimal exertion and dry cough. (A) Axial HRCT image shows bilateral fairly symmetrical subpleural ground glass opacification and reticulations with traction bronchiolectasis suggesting fibrotic NSIP. (B) Axial mediastinal image show patulous esophagus with air fluid level within. 


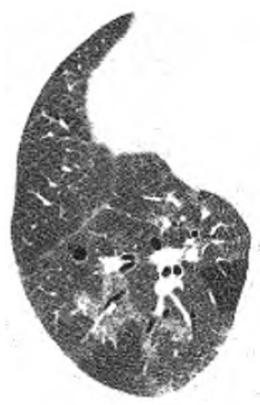

(A)

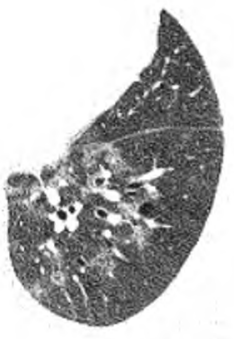

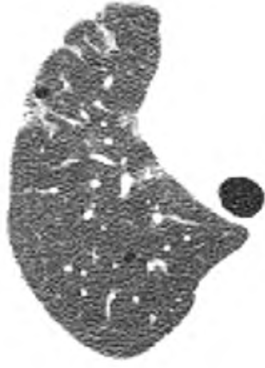

(B)

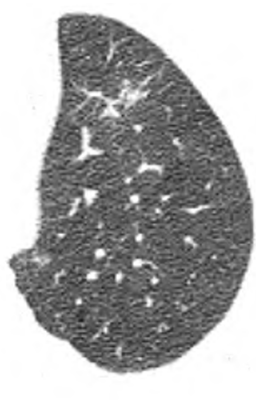

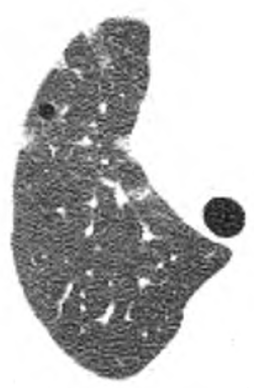

(C)

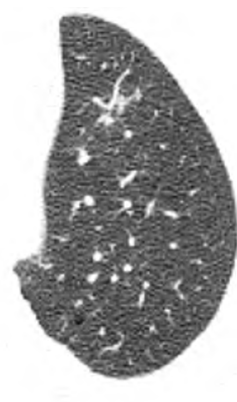

Fig. (3): 42-year-old female patient known case of mixed connective tissue disease presenting with dry cough and dyspnea. $(\mathrm{A}, \mathrm{B}, \mathrm{C})$ Axial images show few tiny air containing subpleural cysts with bilateral basal ground glass opacifican denoting early interstitial pneumonia with cysts suggesting LIP.

Fig. (4): 39-year-old female patient known case of Rheumatoid arthritis presenting with progressive dyspnea on exertion. (A) Axial HRCT image shows mosaic perfusion with areas of hyperlucency intermingled with areas of normal perfusion. HRCT diagnosis: Bronchiolitis obliterans.
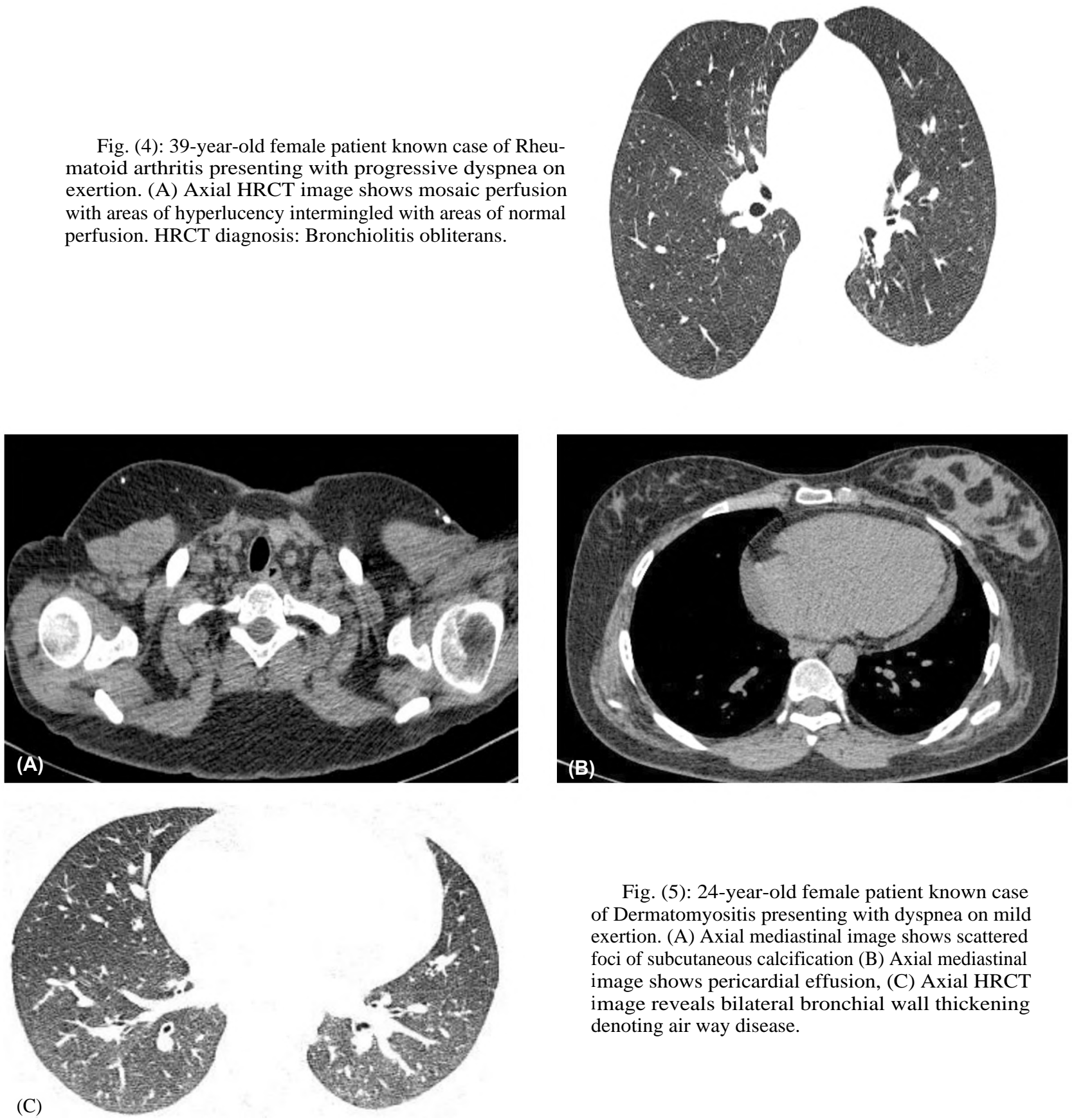

Fig. (5): 24-year-old female patient known case of Dermatomyositis presenting with dyspnea on mild exertion. (A) Axial mediastinal image shows scattered foci of subcutaneous calcification (B) Axial mediastinal image shows pericardial effusion, (C) Axial HRCT image reveals bilateral bronchial wall thickening denoting air way disease. 


\section{Discussion}

This study involved 100 cases diagnosed as CVD with clinical manifestations suggestive of pulmonary affection; HRCT of lungs was done to all cases in Kasr Al Ainy Hospital's radiology department in the period from January 2017 to January 2019.

Interstitial pulmonary fibrosis was noted in $48 \%$ of this study cases, which agrees with Capobianco [11] who stated that IP is one of the commonest forms of thoracic affection among CVD entities.

NSIP was the most common type of IPF among this study cases, found in approximately 24 patients ( $24 \%$ of cases) followed by UIP found in 20 patients (20\% of cases) and LIP was the least common type of ILD (Fig. 3), found in only 4 patients (4\% of cases), which agrees with Capobianco [11] and Silva and Müller [12] who noted the same incidence pattern among different CVD entities.

Six of eight (75\%) MCTD cases had IPF. The incidence stated by Bodolay [13] was $66.6 \%$ of cases and Kinder [14] stated that most of advanced cases of MCTD had ILD.

Airway disease as a single entity was detected in $31(31 \%)$ of patients, which agrees with Lynch [15] who declared the incidence to be $28 \%$ and is less than incidence noted by Silva and Müller [12] who declared the incidence to be $40 \%$ of cases.

Pulmonary hypertension was recorded in 33\% of this study cases, which agrees with Hoeper [16] who reported the incidence to be approximately $30 \%$. Karam [17] reported a higher incidence of $45 \%$.

Thirty-three of studied cases $(33 \%)$ had pericardial affection (Fig. 5) in form of effusion or thickening, which disagrees Silva and Müller [15] and Capobianco [12] who reported a lower incidence of $14 \%$ and $17 \%$ respectively for pericardial affection among CVD entities.

Among patients with RA; none of cases had pericardial effusion, while 5 of $31(16 \%)$ cases had pericardial thickening, which partly agrees with Gauhar [18] as regard rare occurrence of pericardial effusion among RA cases (less than $5 \%$ ) and disagrees with them as regard pericardial thickening incidence noted by him in a higher incidence (50\% of cases). Antin-Ozerkis [19] stated that pericardial affection is commonly noted in cases of RA induced pulmonary hypertension.

Pleural affection was recorded in 12 of studied cases $(12 \%)$, which is much less than incidence noted by Ha et al., [20] and Karam [17] who stated that all CVD groups showed signs of pleural involvement with incidence ranging from 40 and $55 \%$ respectively.

Among cases of DM, none had pleural effusion and or thickening, which agrees with Marie [21] and Fathi [22] who stated their DM cases had no signs of pleural involvement.

Cardiomegaly was noted in $17 \%$ of CVD cases, which is close to incidence noted by Karam [17] who reported the incidence to be $14 \%$.

Among patients with SLE, 6 cases (25\%) of cases had cardiomegaly with 4 of cases having associated pleural effusion and 4 of cases having associated pericardial effusion, which is lower than incidence reported by Vincze [23] who reported cardiomegaly in $15 \%$ of their SLE cases.

Mediastinal lymph node enlargement was noted in $34 \%$ of cases, which is lower than incidence reported by Lynch [15] and Silva and Müller [12] who reported the incidence to range from 11 and $14 \%$ respectively.

Esophageal abnormality was recorded in $28 \%$ of cases, which is lower than incidence noted by Karam [17] and Chung [24] reported by them in 10 and $12 \%$ of cases respectively.

In cases with SSc; esophageal dilatation occurred in 23 of 28 cases (82\%) and was in form of patulous esophagus in 12 cases and air fluid level within esophagus in 11 cases, which agrees with Lynch [15] and Capobianco [11] who stated that esophageal dysmotility was noted in 80 and $90 \%$ of SSc cases respectively and disagrees with Karam [17] who reported a lower incidence of 33\% among his study cases.

\section{Conclusion:}

We concluded that HRCT is fundamental for evaluation of thoracic manifestation of collagen vascular diseases. Early and accurate detection of pulmonary involvement in collagen vascular disease has important therapeutic and prognostic implications because prompt treatment may lead to improved outcomes. So HRCT must be done for any patient with collagen vascular disease even if asymptomatic. 


\section{References}

1- HANNA M.M., MOHAMED A.M. and OSMAN A.M.: Role of High Resolution Computed Tomography in Diagnosis of Interstitial Lung Diseases in Patients with Collagen Diseases. Egyptian Journal of Hospital Medicine, 68 (2), 2017.

2- ELICKER B.M., KALLIANOS K.G. and HENRY T.S.: The role of high-resolution computed tomography in the follow-up of diffuse lung disease: Number 2 in the Series "Radiology" Edited by Nicola Sverzellati and Sujal Desai. European Respiratory Review, 26 (144): 170008, 2017.

3- GRECO F.: HRCT imaging findings of diffuse lung involvement in collagen vascular diseases. European Congress of Radiology, 2017.

4- PONTANA F., BILLARD A.S., DUHAMEL A., SCHMIDT B., FAIVRE J.B., HACHULLA E., MATRAN R., REMY J. and REMY-JARDIN M.: Effect of Iterative Reconstruction on the Detection of Systemic Sclerosisrelated Interstitial Lung Disease: Clinical Experience in 55 Patients. Radiology, 279 (1): 297-305, 2015.

5- CHANSKUL T., DELLARIPA P. and MADAN R.: Intrathoracic rheumatoid arthritis: Imaging spectrum of typical findings and treatment related complication. European Journal of Radiology, 84 (10): 1981-1991, 2015.

6- ALAMOUDI O.S. and ATTAR S.M.: Pulmonary manifestations in systemic lupus erythematosus: Association with disease activity. Respirology, 20 (3): 474-80, 2015.

7- ALETAHA D., NEOGI T., SILMAN A.J., FUNOVITS J., FELSON D.T., BINGHAM III C.O., BIRNBAUM N.S., BURMESTER G.R., BYKERK V.P., COHEN M.D. and COMBE B.: Rheumatoid arthritis classification criteria: an American College of Rheumatology/European League Against Rheumatism collaborative initiative. Arthritis \& Rheumatism, 62 (9): 2569-81, 2010.

8- HUNNINGHAKE G.W., LYNCH D.A., GALVIN J.R., GROSS B.H., MÜLLER N., SCHWARTZ D.A., KING T.E. Jr., LYNCH J.P. III, HEGELE R., WALDRON J., et al.: Radiologic findings are strongly associated with a pathologic diagnosis of usual interstitial pneumonia. Chest, 124: 1215-1223, 2003.

9- DU BOIS R. and KING T.E.: Challenges in pulmonary fibrosis. 5: The NSIP/UIP debate. Thorax., 62 (11): 100812, 2007.

10- SILVA C.I., FLINT J.D., LEVY R.D., MULLER N.L.: Diffuse lung cysts in lymphoid interstitial pneumonia: High-resolution CT and pathologic findings. J. Thorac. Imaging, 21: 241-244, 2006.

11- CAPOBIANCO J., GRIMBERG A., THOMPSON B.M., ANTUNES V.B., JASINOWODOLINSKI D. and MEIRELLES G.S.: Thoracic manifestations of collagen vascular diseases. Radiographics, 30; 32 (1): 33-50, 2011.

12- SILVA C.I. and MÜLLER N.L.: Interstitial lung disease in the setting of collagen vascular disease. In Seminars in roentgenology, 45 (1): 22-28, 2010.
13-BODOLAY E., SZEKANECZ Z., DEVENYI K., GALUSKA L., CSÍPO I., VÈGH J., GARAI I. and SZEGEDI G.: Evaluation of interstitial lung disease in mixed connective tissue disease (MCTD). Rheumatology, 44 (5): 656-61, 2005.

14- KINDER B.W., COLLARD H.R., KOTH L., DAIKH D.I., WOLTERS P.J., ELICKER B., JONES K.D. and KING Jr. T.E.: Idiopathic nonspecific interstitial pneumonia: lung manifestation of undifferentiated connective tissue disease? American journal of respiratory and critical care medicine, 176 (7): 691-7, 2007.

15- LYNCH D.A.: Lung disease related to collagen vascular disease. Journal of thoracic imaging, 24 (4): 299-309, 2009.

16- HOEPER M.M.: Definition, classification, and epidemiology of pulmonary arterial hypertension. InSeminars in respiratory and critical care medicine, 30 (4): 369-375, 2009.

17- KARAM M.B., PEIVAREH H. and MOSADEGH L.: Thoracic Imaging Findings of Collagen Vascular Diseases: A CT Study. Tanaffos, 13 (1): 43, 2014.

18- GAUHAR U.A., GAFFO A.L. and ALARCÓN G.S.: Pulmonary manifestations of rheumatoid arthritis. InSeminars in respiratory and critical care medicine, 28 (4): 430-440, 2007.

19- ANTIN-OZERKIS D., EVANS J., RUBINOWITZ A., HOMER R.J. and MATTHAY R.A.: Pulmonary manifestations of rheumatoid arthritis. Clinics in chest medicine, 31 (3): 451-78, 2010

20- HA Y.J., LEE Y.J. and KANG E.H.: Lung involvements in rheumatic diseases: Update on the epidemiology, pathogenesis, clinical features, and treatment. Bio. Med. Research International, 2018.

21- MARIE I., HACHULLA E., CHERIN P., DOMINIQUE S., HATRON P.Y., HELLOT M.F., DEVULDER B., HERSON S., LEVESQUE H. and COURTOIS H.: Interstitial lung disease in polymyositis and dermatomyositis. Arthritis Care \& Research: Official Journal of the American College of Rheumatology, 47 (6): 614-22, 2002.

22- FATHI M., DASTMALCHI M., RASMUSSEN E., LUNDBERG I.E. and TORNLING G.: Interstitial lung disease, a common manifestation of newly diagnosed polymyositis and dermatomyositis. Annals of the rheumatic diseases, 63 (3): 297-301, 2004.

23- VINCZE K., ODLER B. and MÜLLER V.: Pulmonary manifestations in systemic lupus erythematosus. Orvosi hetilap, 157 (29): 1154-60, 2016.

24- CHUNG J.H., MONTNER S.M., ADEGUNSOYE A. LEE C., OLDHAM J.M., HUSAIN A.N., MacMAHON H., NOTH I., VIJ R. and STREK M.E.: CT findings, radiologic-pathologic correlation, and imaging predictors of survival for patients with interstitial pneumonia with autoimmune features. American Journal of Roentgenology, 208 (6): 1229-1236, 2017. 


\section{دور الأشعة المقطعية عالية الجودة فى تقييم المظاهر الصدرية

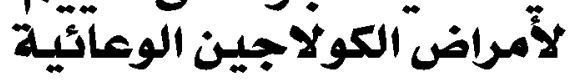

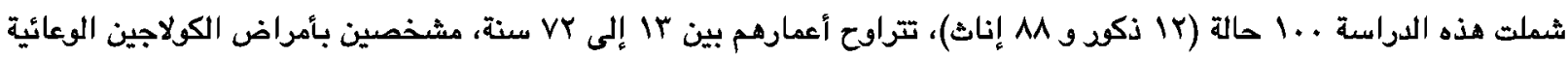

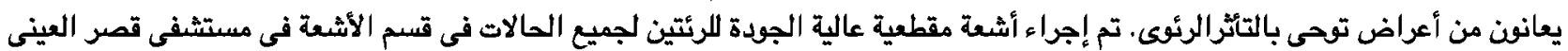

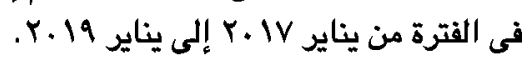

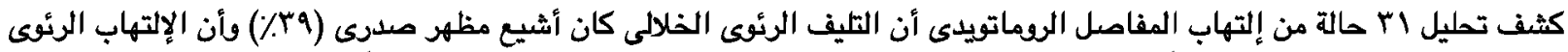

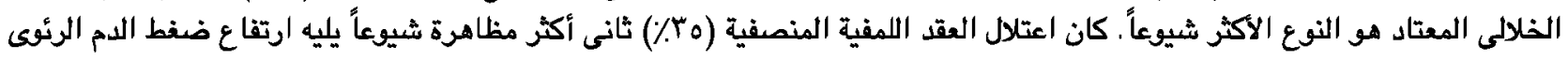

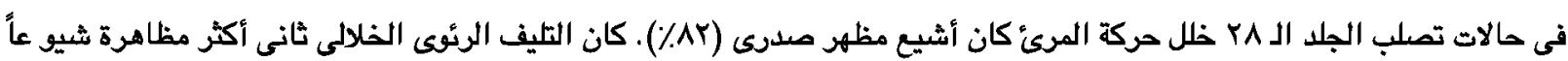

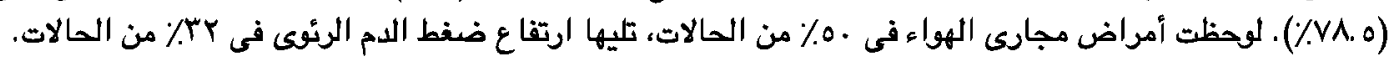

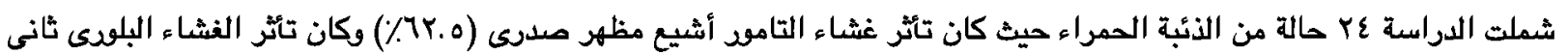

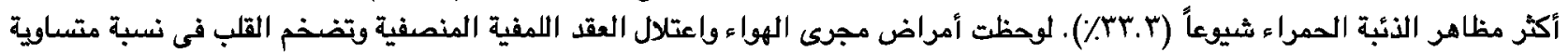
من الحالات (T0\%).

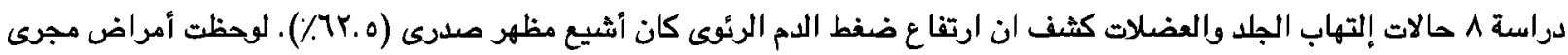

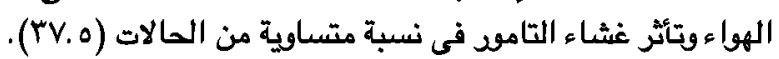

الاستتاج: الأشعة المقطعية عالية الجودة هى المعيار الذهبى فى تقييم المظاهر الصدرية لأمراض الكولاجين الوعائية. ينصح بدراسة

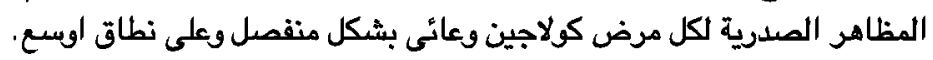

